\title{
RIGHT VENTRICULAR FUNCTIONAL STATUS IN CHRONIC OBSTRUCTIVE PULMONARY DISEASE PATIENT
}

\author{
MA OHAB ${ }^{1}$ DEVENDRA NATH SARKAR ${ }^{2}$, BIDHU BHUSAN DAS ${ }^{3}$, HARIPADA SARKER ${ }^{4}$, M ZAKIR HOSSAIN ${ }^{5}$, \\ SAMPRITY ISLAM ${ }^{6}$, ROWSHAN ALAM ${ }^{7}$, DEVAVRATA SARKAR ${ }^{8}$
}

\begin{abstract}
Aim: To detect the right ventricular status by echocardiography of COPD patients.

Background: Chronic obstructive pulmonary disease is an increasing cause of chronic morbidity and mortality worldwide. Smoking is the major cause and the patients consult with physicians very much late when become complicated. Echocardiography is the main determinant of outcome of COPD patient. We can assess the level of pulmonary hypertension which leads to right heart failure.

Methods : This is a cross sectional study. Study place was Department of Medicine, Rangpur Medical College from $1^{\text {st }}$ July to 30 September 2014. Clinically and post bronchodilator Spiro metrically diagnosed cases were taken. Patients were graded into Mild, Moderate, severe and very severe categories according to GOLD criteria. Statistical analysis was done with echo findings of $R V$ dilatation and hypertrophy by using Chi-square test and statistical significance was taken as $p<0.05$

Results : Mean age was 61.50 (sd \pm 9.76 ) years with male predominance. Mean duration of disease was 6.80 ( $s d \pm 4.71$ ) years. Patients had a mean duration of smoking of $23.2 \pm 3.6$ pack years. ECG and Echo findings such as $R V$ dilatation, $R V$ hypertrophy and pulmonary hypertension were showed significant correlation with severity and duration of disease. Diagnosis of cor-pulmonale was clinically 20\%, ECG 50\% and echocardiographically $92 \%$.

Conclusion : COPD is more common in males in $5^{\text {th }}$ to $7^{\text {th }}$ decade with the smoking history of more than 20 pack years. Most patients have moderate to severe disease at presentation. Echocardiography can detect the RV dysfunction in COPD patient earlier. ECG and Echo findings increase as the severity and duration of the disease increases and echocardiography is better than ECG or clinical methods in detecting $R V$ dysfunction.
\end{abstract}

Received: 26 November 2017

Accepted: 10 June 2018

DOI: http:// dx.doi.org/ 10.3329/ bjmed.v29i2.37940

\section{Introduction}

Chronic Obstructive Pulmonary Disease (COPD) is currently the fourth leading cause of death in the world but is projected to be the $3^{\text {rd }}$ leading cause of death by 2020. More than 3 million people died of COPD in 2012 accounting for $6 \%$ of all deaths globally. COPD represents an important public health challenge that is both preventable and treatable. COPD is a major cause of chronic morbidity and mortality throughout the world; many people suffer from this disease for years, and die prematurely from it or its complications. Globally, the COPD burden is projected to increase in coming decades because of continued exposure to COPD risk factors and aging of the population. ${ }^{1}$

The chronic air flow limitation of COPD is caused by a mixture of small airway disease (Obstructive

1. Associate Professor of Medicine, Rangpur Medical College, Bangladesh

2. Professor and Head, Department of Medicine, Rangpur Medical College, Bangladesh

3. Professor of Medicine, Rangpur Medical College, Bangladesh

4. Assistant Professor of Cardiology, Rangpur Medical College, Bangladesh

5. Professor of Medicine, Shaheed Ziaur Rahman Medical College, Bangladesh.

6. Medical Officer, Department of Medicine, BSMMU

7. Assistant Professor of Community Medicine, Rangpur Medical College \& General Secretary (IPCRG-Bangladesh

8. Medical Doctor, Enam Medical College Hospital, Savar, Dhaka.

Address of Correspondence: Dr. MA Ohab, Associate Professor of Medicine, Rangpur Medical College, Bangladesh

Bangladesh J Medicine 2018; $29: 63-68$ 
bronchitis) and parenchymal destruction (Emphysema), the relative contribution of which vary from person to person. ${ }^{2}$

Smoking is the leading cause of development of COPD. Most of the people of this region are habituated with smoking. Others factors includes occupational dusts and chemicals, indoor and outdoor air pollution, childhood infection and socio-economic status (risk of developing COPD is inversely related to socio-economic status).

COPD is characterized by slowly progressive airflow obstruction, resulting in dyspnoea and exercise limitation and pulmonary arterial hypertension is its major cardiovascular complication. ${ }^{3}$

Right ventricular (RV) hypertrophy or dysfunction is common in patients with COPD particularly in those with low oxygen saturation. It occurs in up to $50 \%$ of the patients with moderate to severe COPD. ${ }^{4}$ When present, it can reduce exercise tolerance, increase dyspnoea, and contribute to an overall decrease in functional status, and indicate a higher mortality rate. Its early recognition and treatment may lead to prolonged survival and improved quality of life.

COPD is the $4^{\text {th }}$ of the most important causes of death and is predicted to the $3^{\text {rd }}$ most common cause of death and $5^{\text {th }}$ most common cause disability worldwide by the year 2020. ${ }^{5}$

According to BOLD-BD ( Burden of Obstructive Lung Disease in Bangladesh ) Study- 2007, Prevalence in $>40$ years of age is $21.24 \%$ \& total population is $4.3 \%$ and total burden of COPD patients is about 6 million. ${ }^{6}$

Smoking more than 10 pack years ( 20 sticks per day for 1 year $=1$ pack year) is the cause in $65-70 \%$ cases of COPD in people aged 40 years or more in Bangladesh. Smoke from biomass fuel burning is an important risk factor for COPD particularly in rural and sub-urban housewives 35\% female suffering from COPD. ${ }^{7}$

\section{Methods:}

This is a cross sectional study done in department of Medicine, Rangpur Medical College Hospital, Rangpur. From July 2010 to June 2012 in COPD patients admitted at medicine department at Rangpur Medical College Hospital, Rangpur. All COPD patient will be selected purposively during the study period as per inclusion and exclusion criteria. Evaluation of the patient will be done on the basis of history, physical examination and investigation. A thorough physical examination with special attention to measurement of severity of COPD by Spirometer. Detailed history was taken from all the patient selected for the study. Investigations were done. All the data generated were recorded in pre-designed case record form. Study subject were classified into four groups as mild, moderate, severe and very severe type of COPD.Measurement of COPD was done by
Spirometer and evaluation of cardiac status by Clinical, Chest X-ray, ECG and Echocardiography (2D and color Doppler).

\section{Result}

Within this pilot, cross-sectional assessment, the total number of 100 patients were studied. The mean age was 61.50 (SD \pm 9.76$)$ years. Age range was 42 to 100 years. The maximum incidence of COPD in this study is among the age group 50 to 69 years i.e. in the $6^{\text {th }}$ and $7^{\text {th }}$ decade $(74 \%)$. No patients were under the age of 42 years, only $4 \%$ of the patients were e" 80 years. In this study $90 \%$ patients were male and $10 \%$ were female. Male are preponderance. In our study group $90 \%$ population are from rural and $10 \%$ from urban.

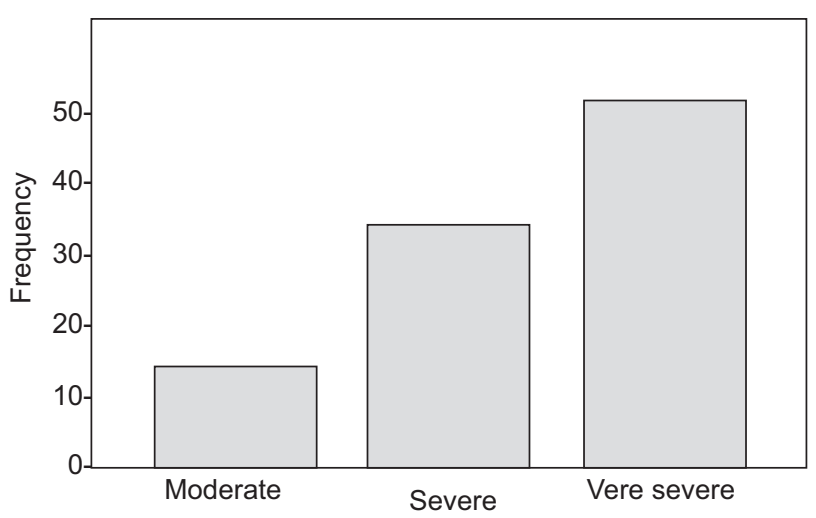

Fig.-1 : Severity of Disease

Majority of the respondents sufferings from right ventricular functional impairment were under the age group from 50 to 59 years. Male $(88.2 \%)$ were more affected. Rural (100\%) farmers (76.5\%) under low (94.1\%) socioeconomic status had more right ventricular functional impairment.

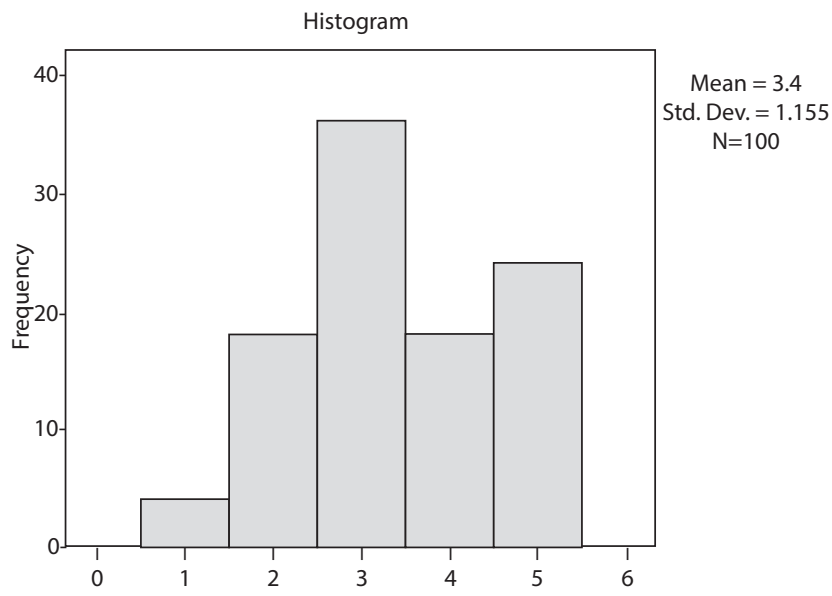

Fig.-2: History of Smoking 
The most common RVH criteria of this study group were by $\mathrm{R} / \mathrm{S}$ in $\mathrm{V}_{1}>1$ and $\mathrm{R}$ in $\mathrm{V}_{1}>7$ in $50 \%$, right axis deviation in $26 \%$. P-pulmonale was $46 \%$.Statistical significant was found in $\mathrm{R} / \mathrm{S}$ in $\mathrm{V}_{1}>$ 1 and $\mathrm{R}$ in $\mathrm{V}_{1}>7$ and right axis deviation but not found in P-pulmonale.

Table-I

Analysis of Echo findings among the study population $(n=100)$. (2D and color Doppler)

\begin{tabular}{lcc}
\hline Echo findings & $\begin{array}{c}\text { Frequency } \\
\text { Present+Absent } \\
=\text { Total }\end{array}$ & $\begin{array}{c}\text { Percentage } \\
(\%)\end{array}$ \\
\hline RV. Wall hypertrophy & $92+8=100$ & 92 \\
RV. Dilatation & $50+50=100$ & 50 \\
IVS motion abnormality & $08+92=100$ & 08 \\
Pulmonary hypertension & $28+72=100$ & 28 \\
\hline
\end{tabular}

$50 \%$ of the patient in this study had echocardiographic evidence of right ventricular dilatation. $92 \%$ of patients had echocardiographic evidence of right ventricular hypertrophy. $28 \%$ of the patients had echocardiographic evidence of pulmonary hypertension and $8 \%$ of patient had evidence of interventricular septal motion abnormality.

Table-II

Association of Echo findings with severity of symptoms.

Echo Findings Absent Severe Moderate Very Total

\begin{tabular}{lccccc} 
& & & \multicolumn{3}{c}{ Severe } \\
\hline RV dilation & 50 & 02 & 12 & 36 & 100 \\
RV hypertrophy & 08 & 12 & 34 & 46 & 100 \\
Pulmonary & 72 & 02 & 06 & 20 & 100 \\
hypertension & & & & & \\
IVS motion & 92 & 00 & 02 & 06 & 100 \\
abnormality & & & & & \\
\hline
\end{tabular}

\section{Discussion}

The maximum numbers of COPD patients (74/100) in this study were in the age group of 50-69 years with mean age $59.94( \pm 10.37)$ years, which is similar to previous studies. The mean age of the patient in the other studies shows, Gupta and Khastgir et al 1989,50.2( \pm 12 yrs) 8 Putnik and Povazan, 1998,(59.25) yrs. ${ }^{9}$ Most Patients from the age group between 50-70 yrs are admitted, mainly because of the longer duration of tobacco exposure and repeated respiratory tract infections, which would have compromised their quality of life.

In this study the male : female ratio was 9:1, i.e. males form $90 \%(90 / 100)$ of the study subjects. This higher incidence of COPD in males can be attributed due to more habituated with smoking. In our study both males and females were smokers as tobacco is widely cultivated in this region and easily available. Males, Females ratio in other studies: J. C. Banergea 1966, Percentage of male 80\%, Chappell A. G. 1966, Percentage of male $81.25 \%$, Benjamin Burrows et al 1972 ,Percentage of male $92 \%$, V. K. Singh et al 1989 , Percentage of male $94.6 \%$. In present study the percentage of male is $90 \%$, which is similar with other studies.

In this study most of the patients (50/100) gave history of symptoms of 1-5 years duration, with a mean duration of dyspnoea and cough of $6.80 \pm 4.71$ years. In the study conducted by Gupta et al, 1989,8 the mean duration of symptoms was $8.9 \pm 4.9$ years and in the study of J. C. Banergae, the mean duration of cough was 5.4 yrs and dyspnoea was 1.94 years.

In the present study, 52\% (52/100) of the patients had $\mathrm{FEV}_{1}<30 \%$ of the predicted i.e. very severe obstructive disease. As we already know, patients start experiencing breathlessness on any exertion when the $\mathrm{FEV}_{1}$ fall to $<40 \%$ (acc to BTS) and according to Gold criteria, patients usually experience worsening dyspnoea when the patient has $\mathrm{FEV}_{1}<50 \%$ of predicted. Thus they tend to seek medical attention during this stage, accounting for the majority of patients who have very severe and severe obstructive defect. Patients with mild ( $\mathrm{FEV}_{1}>80 \%$ ) and moderate obstructive defect, that is $\mathrm{FEV}_{1} 50-80 \%$ of predicted are usually in the pre symptomatic stage and are not likely to come to medical attention, unless they develop an exacerbation or lower respiratory tract infection. This accounts for the fact that only 14\% of the patients are in moderate category and no one of mild category was found in this study.

The stages of COPD were found in the study of Gupta \& Khastgir, ${ }^{8}$ Mild 1(3.48\%), Moderate 5(17.20\%), and Severe 239 (79.32\%). In Highamet al,1988, Mild $12(16.4 \%)$, Moderate 19(26\%), Severe 42(57.6\%). Present study shows, Mild nil, Moderate 14\%, Severe $34 \%$ and Very severe $52 \%$. So it is seen that the findings of this study correlate with the previous studies.

Majority of the patients $(36 / 100)$ had a history of tobacco use of at least 20-29 pack years, with a mean of 23.2 years $( \pm 3.6)$. And according to BTS guide lines most patients with COPD have at least in 20 pack 
years of smoking history. Our findings correlate well with this. And $70 \%$ of the patients with severe disease had more than 20 pack years of exposure correlates with this. In the study by Gupta and Khastgir mean of $26.4( \pm 16.1)$ pack years of smoking history was found, which is similar to the present study. ${ }^{8}$ In the study of J. C. Banergea, Dyspnoea 73(97.3\%) Cough with / without sputum 69(92\%) / 63(84\%). Present study shows, Dyspnoea $100 \%$, Cough with or without sputum $88 \%$,. The findings of our study correlate with this study.

Most of the patients in the present study had tachypnea on presentation. Most of them had signs of hyperinflation, and also diminished breath sounds with prolonged expiratory phase. Clinical signs of right ventricular hypertrophy was present in $20 \%$ (20/ $100)$ of the patients and pulmonary hypertension in $18 \%(18 / 100)$ of the patients. This can be explained by the fact that clinical signs of pulmonary hypertension and cor pulmonale are usually found in the advanced cases and more over are masked due to the hyperinflation of lungs. In a study carried out by Gupta and Khastgir 1989, where shows Tachypnoea $30(100 \%)$, Cyanosis $15(50 \%)$, Epigastric pulsation $30(100 \%)$, Parasternal heave $15(50 \%)$, Loud $\mathrm{P}_{2}$ 17(57\%), CCF 23(77\%). ${ }^{8}$ Present study shows Tachypnoea 100(100\%), Cyanosis 24(24\%), Epigastric pulsation $14(14 \%)$, Parasternal heave 20(20\%), Loud $\mathrm{P}_{2}$ 18(18\%), CCF 26(26\%). Findings of our study were correlate fully with the study of Gupta and Khastgir. ${ }^{8}$

Most of the patients in the present study had X-ray evidence of emphysema i.e. signs of hyperinflation like low flat diaphragm, hyper translucency etc. In a study carried out by Gupta and Khastgir, 1989 where shows Emphysema 16(53\%), Cardiomegaly 6(20\%) and Prominent right pulmonary artery $11(36.7 \%) .8$ Present study shows Emphysema 54(54\%), Cardiomegaly 26(26\%) and Prominent right pulmonary artery 40(40\%). Our study correlates with the previous study.

Right ventricular hypertrophy was found in 26\% (26/ 100) of the patients in the present study. According to Murphy \& Hutcheson, right axis deviation is one of the most reliable criteria of $\mathrm{RVH}$, and is more common in patients with RVH secondary to COPD than in those with RVH secondary to congenital heart disease and has a specificity of $95 \%$. Millard concluded that in chronic pulmonary disease, the position of mean QRS axis provided as good an indication of right ventricular hypertrophy as any other electrocardiographic sign. Other studies,Phillips (1958) and Roman (1961) ${ }^{10}$ also emphasized the value of right axis deviation as a sign of RVH. Our findings are in agreement with the above studies.

Comparison with other studies shows Milnor, 1957 11 18.75\%, Padmavathi and Pathak, 1959, 74\%, Silver and Calatayud, 1971, 19\%, Padmavathi And Raizada 1972,12 43.2\%, Murphy and Hutcheson, 1974, 28\%, Gupta and Khastgir 1989,8 33.3\%, Present study $26 \%$.

Thus it is evident that the incidence of RAD ranges from $19 \%-74 \%$ and the finding in this study of $26 \%$ falls within this range.

The incidence of $\mathrm{R} / \mathrm{S}$ in $\mathrm{V}_{1}>1$ in the study of Fowler et al, 1965 was 53\%, Silver and Calatayud, 1971 was $7 \%$, Murphy and Hutcheson, 1974 was $7.5 \%$. Present study $30 \%$. Thus the incidence of $\mathrm{R} / \mathrm{s}$ in $\mathrm{V}_{1}>1$ ranges from $7-53 \%$ and the finding of $30 \%$ in the present study falls within this range.

The incidence of $\mathrm{R}$ in $\mathrm{V}_{1}>7 \mathrm{~mm}$. in the study of Fowler et al, 1965, 7\%, Silver and Calatayud, 1971, 21\%, Murphy and Hutcheson, 1974, 9.4\%, 12 Padmavathi and Raizada, 1972, 12 2.6\%. Present study 24\%. The incidence of $\mathrm{R}>7 \mathrm{~mm}$ in $\mathrm{V}_{1}$ ranges from $2.6 \%-21 \%$ and the finding of $24 \%$ in this study is similar.

The incidence of $\mathrm{S}<2 \mathrm{~mm}$. in $\mathrm{V}_{1}$ in the study of Sokolow and Lyon, 1949, was 50\%, Silver and Calatayud, 1971, was $3 \%$ and present study shows $8 \%$. Marked shortening of ' $\mathrm{s}$ ' wave in lead $\mathrm{V}_{1}$ is one of the 'suggestive' criteria for RVH by Phillips and Burch.

The incidence of RBBB in the study of K. K. Datey, 1960, was 6\%, 12 Padmavathi and Raizada, 1972, ${ }^{12}$ was $12.9 \%$, Murphy and Hutcheson, 1974, was $2 \%$ Present study 36\%. Caird and Wilcken state that, incomplete RBBB is considered by some as good evidence of the presence of RVH but not of its degree. Phillips and Burch have included this criteria among the fairly conclusive criteria for RVH.

The incidence of P-pulmonale in the study of $\mathrm{K}$. K. Datey, 1960,was 32.4\%, Padmavathi and Raizada, 1972, was 95\% Murphy and Hutcheson, 1974, was 26.4\%, Silver and Calatayud, 1971, was 46.2\%, Caird and Wilcken was 36.7\%, Fowler et al, 1965, was 33\%, Gupta and Khastgir 1989, was 43.3\%. Present study shows $46 \%$. The findings of $\mathrm{p}$-pulmonale in this study is similar to Gupta and Khastgir ${ }^{8}$ (43.3\%).

In the present study, the incidence of all the ECG findings, increased as the severity of the disease (as measured by $\mathrm{FEV}_{1}$ and graded according to GOLD criteria) increased. 
Statistical correlation, was found with right axis deviation, incomplete RBBB, R/S in $\mathrm{V}_{1}>1$ and $\mathrm{RVH}$, which was also significant (i.e. $\mathrm{p}<0.05$ ). This means that the increase in incidence of the above ECG findings, with increasing severity (decreasing $\mathrm{FEV}_{1}$ ) was statistically significant.

The incidence right axis deviation, incomplete RBBB, $\mathrm{R} / \mathrm{S}$ in $\mathrm{V}_{1}>1$ and right ventricular hypertrophy increased as the duration of symptoms increased, which was statistically significant $(\mathrm{p}<0.05)$.

The data regarding duration of symptom is solely based on history the patient gives, and the patient usually disregards minimal symptoms of cough and breathlessness, which may be present for many years, without affecting his daily life.

The findings of correlation are also affected by the fact that maximum number of patients are found in (1-5) year duration group (50\%) and in the $>10$ years duration groups only $16 \%$ of the patients were found. Therefore we can say that RAD, RVH, R/S in $\mathrm{V}_{1}>1$ and incomplete RBBB which are ECG signs of cor pulmonale, are found with increasing incidence as duration of symptoms increases which are statistically significant and findings of poor progression of ' $r$ ' wave, which are ECG signs of emphysema bear no correlation with duration of the symptoms.

All the echocardiographic findings generally showed an increasing trend in the incidences, with increasing duration of symptoms.

Statistically significant correlation was found with RV wall hypertrophy, pulmonary hypertension, IVS motion abnormality and cor pulmonale, whose incidence was significantly higher with longer the duration of the symptoms.

This can be explained by the fact that longer the duration of the symptoms, higher is the chances that the patient has developed pulmonary hypertension and cor pulmonale and also right heart failure.

This clearly shows that echocardiography is better than ECG or clinical methods, to detect the presence of cor pulmonale in patients with COPD.

It is well known that clinical signs are often difficult to detect in patients with COPD, because of over inflation of chest and posterior rotation of heart. Extra heart sounds and the murmur of tricuspid regurgitation, which are best heard in inspiration, all suggest R. V. dysfunction, but again may be obscured by over inflation. The jugular venous pressure is often difficult to assess due to large swings in intra thoracic pressure.
Peripheral edema may be due to other causes such as hypo albuminemia. These signs develop late in the clinical course in patients with COPD and are not sensitive indicators of pulmonary hypertension or R.V. hypertrophy. ${ }^{13}$

\section{Conclusion}

Echocardiography can detect the RV dysfunction in COPD patient earlier. Echocardiography is better than ECG.Clinical methods is need to detect $R V$ dysfunction.

\section{Acknowledgement:}

This study was supported by department of medicine and department of community medicine, Rangpur Medical College, Bangladesh.

\section{Conflict of interest declaration:}

We declare there are no conflicts of interest related with the research presented.

\section{References:}

1. GOLD (Global Initiative for Chronic Obstructive Lung Disease) - Global Strategy for Diagnosis, Management, and Prevention of Chronic Obstructive Pulmonary Disease. http.//www.goldcopd.com (accessed.2018).

2. Nicki R. Colledge, Brian R. Walker, Struat H. Ralston.2010. Davidson's principles \& Practice of Medicine, 21st Edition: CHURCHILL LIVINGSTONE, Elsevier 646,671-673,720.

3. Higham M A, Dawson D, Joshi J, Nihoyanno P P, Morell $\mathrm{N}$ W. Utility of Echocardiography in assessment of pulmonary hypertension secondary to COPD. Eur. Respir. J. 2001; 17: 350-355

4. James $\mathrm{R} \mathrm{K}$, Nicholas $\mathrm{S} \mathrm{H}$, Right ventricular dysfunction in chronic obstructive pulmonary disease, Evaluation and management. Chest 1991; 99: 715-23.

5. Parveen Kumar, Michael Clark. Kumar and Clark's Clinical Medicine, $7^{\text {th }}$ edition. Spain : SUNNDERS ELSEVIER, 2009; 830-835

6. Burden of Obstructive Lung Disease in Bangladesh ( BOLD- BD) conducted by BANGLADESH LUNG FOUNDATION, Report on National COPD study, 2007.

7. Bangladesh lung health manual October 2010; Vol2: P-6

8. Gupta S, Khastgir T, Gupta M P, Sethi K K, Manoharan S. Clinical, Haemodynamic and Echocardiographic study in chronic cor pulmonale. JAPI $1989 ; 37(6)$ : 373-376.

9. Putnik M, Povazan D, Vindisjesic M. Electrocardiography and echocardiography in the diagnosis of chronic cor pulmonale (Article in Serbo Croatian (Roman)). Med Pregl, 1998 ; 51(11) : 528-31. 
10. Phillips R W, Providence R I. The electrocardiogram in Cor pulmonale secondary to pulmonary emphysema. A study of 18 cases proved by autopsy. American Heart Journal, 1958; 56(3): 352-371.

11. Milnor W R. Electrocardiogram and Vectorocardiogram in right ventricular hypertrophy and right bundle branch block. Circulation 1957; XVI. : 348-367.

Millard F J C. The electrocardiogram in chronic lung disease. British heart journal 1967; 29: 435019 .
12. Padmavathi S and Veena Raizada. Electrocardiogram in chronic cor pulmonale. British Heart Journal 1972; 34: 658-667.

13. William MacNee. Chronic bronchitis and emphysema. Chapter 23. Crofton and Douglas' Respiratory Diseases. Anthony Seaton, Douglas Seaton, Gordon Leitch, 5 edition. Black well science Ltd. London. 2000 : 616-695

14. Arthus J T. Chronic pulmonary heart disease. British Heart Journal, 1972; 34: 653-657. 